\title{
Penerapan Program Edukasi Perawatan Kaki (3STEPFUN) dalam Meningkatkan Perilaku Merawat Kaki untuk Pencegahan Ulkus Diabetikum pada Pasien Diabetes Mellitus Tipe 2 di Aliansi Rumah Sakit Islam Jakarta Tahun 2019
}

\author{
Umi Kalsum, Syaefunnuril Anwar $\mathrm{H}$, Astrid $^{1}$, Jamari \\ Prodi Spesialis Keperawatan Medikal Bedah Fakultas IImu Keperawatan \\ Universitas Muhammadiyah Jakarta \\ Email : umi_kalsum44@gmail.com
}

\begin{abstract}
Abstrak
Ulkus diabetik merupakan komplikasi diabetes mellitus yang menjadi ancaman dan tantangan secara global di dunia dikarenakan perawatan untuk ulkus kaki diabetik ini sangatlah rumit dan mahal. Selain itu tingkat kekambuhan diperkirakan terjadi sekitar $40 \%$ hingga $65 \%$ kasus diabetes dalam lima tahun pertama pasien menderita diabetes mellitus. Dampak lanjutan dari kejadian ulkus kaki diabetikum ini adalah terjadinya kematian dan amputasi. Tujuan pelaksanaan tindakan ini adalah untuk menerapkan salah satu metode pencegahan terjadinya ulkus diabetikum yaitu perawatan kaki secara mandiri oleh pasien penderita diabetes mellitus dengan pemberian intervensi pendidikan perawatan kaki yang berbasis teori self-efficacy (3STEPFUN) dan mengevaluasi perilaku pasien dalam melakukan perawatan kaki secara mandiri (Foot Self Care). Intervensi ini di lakukan satu kali pada minggu pertama dan akan di pantau pelaksanaan perawatan kaki mandiri pada minggu kedua dan di evaluasi pada minggu ke empat mengenai kondisi kaki pasien diabetes mellitus tersebut. Sampel yang di gunakan berjumlahh 30 sampel. Hasil dari penerapan intervensi di dapatkan data perilaku perawatan kaki responden di rumah sebagian besar baik yaitu melakukan perawatan kaki di rumah dengan baik dan rutin di lakukan di rumah sebanyak 28 responden (93.4 \%). Dan resiko terjadinya ulser pada minggu ke-4 di bandingkan pada minggu ke-1 meningkat menjadi kategori sedang sebanyak 2 responden $(6.6 \%)$ dan meningkat menjadi kategori tinggi sebanyak 1 responden (3.4\%). Dari hasil tersebut Perawat di harapkan dapat meningkatkan komunikasi efektif dengan pasien dan keluarga sehingga dapat meningkatan frekuensi dan kualitas promotive kesehatan mengenai penyakit diabetes mellitis terutama pencegahan komplikasi diabetes mellitus
\end{abstract}

Kata kunci: Edukasi, Perawatan Kaki Sendiri, Ulkus Diabetikum, Diabetes Mellitus Tipe 2

\begin{abstract}
Diabetic ulcer is a complication of diabetes mellitus which is a threat and challenge globally in the world because the treatment for diabetic foot ulcers is very complicated and expensive. In addition, the recurrence rate is estimated to occur around $40 \%$ to $65 \%$ of diabetes cases in the first five years of a patient suffering from diabetes mellitus. The continued impact of the occurrence of diabetic foot ulcers is death and amputation. The purpose of implementing this action is to apply one of the methods of preventing diabetic ulcers, namely independent foot care by patients with diabetes mellitus by providing foot care education interventions based on self-efficacy theory (3STEPFUN) and evaluating patient behavior in doing foot care independently ( Foot Self Care). This intervention is carried out http://ejournal.urindo.ac.id/index.php/kesehatan
\end{abstract}

Article History :

Sumbitted 01 Desember 2020, Accepted 29 Desember 2020, Published 31 Desember 2020 
once in the first week and will be monitored for the implementation of independent foot care in the second week and evaluated at the fourth week regarding the condition of the patient's feet with diabetes mellitus. The sample used is 30 samples. The results of the application of the intervention obtained data on the behavior of respondents' foot care at home, mostly good, namely performing foot care at home properly and routinely at home as many as 28 respondents (93.4\%). And the risk of developing ulcers at week 4 compared to week 1 increased to the medium category by 2 respondents (6.6\%) and increased to the high category by 1 respondent (3.4\%). From these results it is hoped that nurses can improve effective communication with patients and families so that they can increase the frequency and quality of health promotive regarding diabetes mellitis, especially the prevention of complications of diabetes mellitus.

Keywords: Education, Foot Self Care, Ulcer Diabeticum, Diabetes Mellitus Type 2

\section{PENDAHULUAN}

Berdasarkan wawancara dengan pasien Diabetes Mellitus dengan Tipe 2, sebagian besar pasien mengetahui bagimana cara mengontrol gula darah dengan pemberian obat baik obat oral maupun dengan suntik insulin, pasien juga mengetahui bagaimana menjaga pola makannya dengan mengkonsumsi makanan rendah karbohidrat. Tetapi sebagian besar pasien juga tidak mengetahui bagimana cara mencegah terjadinya komplikasi penyakit diabetes mellitus terutama pencegahan terjadinya luka atau ulkus diabetikum yang saat ini gejala-gejala paling banyak di keluhkan oleh pasien.

Beberapa gejala pada pasien seperti kaki kesemutan, baal atau bahkan kesakitan selanjutnya di sebut dengan istilah neuropati perifer. Neuropati perifer merupakan salah satu komplikasi mikrovaskuler yang paling umum dan dapat berkembang hingga $50 \%$ dari pasien diabetes mellitus (Sahay \& Srinagesh, 2011). Neuropati perifer diabetik bermanifestasi dalam gejala klinis yang berbeda-beda sepertinya adanya paresthesia, dysesthesia, maupun perubahan dalam pergerakan. Selian itu pasien yang mengalami neuropati perifer akan proprioception, refleks tendon dalam yang hipoaktif, adanya kelemahan motorik, dan juga nyeri neuropatik (Donnan \& Ledger, 2006; Gedik \& Demir, 2008).

Komplikasi lanjutan setelah pasien mengalami neuropati perifer adalah ulkus diabetikum. Ulkus ini sering menyerang pada ekstremitas bawah (kaki) pasien. Ulkus diabetik ini merupakan komplikasi diabetes mellitus yang menjadi ancaman dan tantangan secara global di dunia. Dimana Prevalensi kejadian ulkus kaki diabetikum secara global adalah 6,3\% (Zhang P, 2017). Perawatan untuk ulkus kaki diabetik ini 
sangatlah rumit dan mahal. Selain itu tingkat kekambuhan diperkirakan terjadi sekitar 40\% hingga 65\% kasus diabetes dalam lima tahun pertama pasien menderita diabetes mellitus (Armstrong DG, 2017). Dampak lanjutan dari kejadian ulkus kaki diabetikum ini adalah terjajdinya kematian dan amputasi yang terjadi pada hampir sepertiga dari kasus (Hoa LT, 2014). Beberapa penelitian yang telah di lakukan oleh Asian Asociation for the study of diabetes (2010), menggambarkan bahwa ulkus kaki diabetikum merupakan permasalahan untuk perawat dan juga pasien yang selanjutnya merupakan tantangan bagi sistem perawatan kesehatan secara lebih luas lagi. Dan pencegahan merupakan hal utama pada ulkus kaki diabetikum yang sangat diperlukan di banding dengan penelitian sebelumnya.

Ulkus kaki diabetik sebagian besar dapat dicegah oleh pasien itu sendiri. Di antara strategi pencegahan salah satunya adalah dengan pendidikan kesehatan yang di berikan oleh perawat pada pasien yang dianggap perlu dan dapat meningkatkan pengetahuan pasien tentang masalah kaki terkait diabetes, perilaku perawatan kaki dan mengurangi masalah kaki seperti neuropati, kecacatan kaki, lesi, maag, tinea pedis, dan kalus (Sharoni, 2016). Namun demikian, bukti efektivitas pendidikan saja tanpa langkah-langkah pencegahan tambahan dalam mengurangi terjadinya ulkus dan amputasi tidak cukup sehingga memerlukan tindakan lanjut dari pendidikan kesehatan tersebut (Dorresteijin JA, 2014).

Akhir-akhir ini semakin banyak intervensi berbasis teori dalam pendidikan pasien untuk mencegah terjadinya ulkus kaki diabetikum yang telah dipublikasikan. Teori Kognitif Sosial atau Self-efficacy Teori Bandura adalah salah satu yang paling sering diterapkan dalam studi pendidikan perawatan kaki yang dapat diidentifikasi, dan efektivitas program pendidikan perawatan kaki berbasis teori juga dikonfirmasi efektif dalam pemberian pendidikan kesehatan (Bicer EK, 2016). Dan banyak para peneliti merekomendasikan bahwa program intervensi manajemen diri diabetes yang didukung oleh teori ini harus di kembangkan dan disesuaikan untuk orang dewasa yang mengalami diabetes mellitus.

Terdapat peneliti yang di pimpin oleh Thi Phuong Lan Nguyen (2019) bekerjasama antara Queensland University Technology Australia, dan Ho Chi Minh City University of Medicine and Pharmacy Vietnam, yang mengembangkan program intervensi pendidikan perawatan kaki berbasis teori self-efficacy (3STEPFUN) dan mengevaluasi efektivitas program pada perilaku perawatan kaki dan masalah pada kaki yang 
di dahului terjadi ulserasi kaki untuk orang dewasa dengan diabetes mellitus dengan risiko rendah terjadinya ulkus kaki.

Dari uraian di atas, kami mahasiswa program Spesialis Keperawatan Medikal Bedah (Sp.KMB) dengan Kekhususan Sistem Endokrin tertarik untuk melakukan tindakan keperawatan berdasarkan Evidance Base Nursing (EBN) untuk mengatasi masalah keperawatan yang di alami oleh pasien diabetes mellitus yang mengalami resiko terjadinya ulkus kaki diabetikum seperti neuropati perifer yaitu dengan pemberian intervensi pendidikan perawatan kaki yang berbasis teori self-efficacy (3STEPFUN) dengan mengevaluasi perilaku pasien dalam melakukan perawatan kaki secara mandiri (Foot Self Care).

\section{METODE}

Pendidikan kesehatan yang akan di kembangkan saat ini untuk pasien diabetes mellitus dengan ulkus kaki diabetikum ataupun yang memiliki resiko terjadinya ulkus adalah dengan penerapan pendidikan kesehatan berdasarkan teori foot self care atau efikasi dengan metode 3STEPFUN yang terdiri dari :

1. Pendidikan kesehatan pada kelompok kecil dan pemberian keterampilan secara langsung selama 60-75 menit.
2. Memberikan perlengkapan perawatan kaki dan tata cara perawatan kaki secara tertulis.

3. Di tindak lanjuti selama 1 bulan dengan melakukan panggilan telpon $s$ pada minggu ke-2 untuk mendapatkan informasi mengenai kegiatan perawatan kaki secara mandiri.

Adapun evaluasi efektifitas pelaksanaan penerapan pendidikan kesehatan tersebut adalah dengan melakukan evaluasi terhadap perilaku perawatan kaki dengan menggunakan format FSCB (Foot Self Care Behaviour).

Populasi dalam pelaksanaan evidence base practice (EBP) ini adalah pasien yang menderita diabetes mellitus tipe 2 tanpa ulkus diabetikum tetapi memiliki tanda gejala resiko terjadinya ulkus diabetikum seperti neuropati perifer.

\section{HASIL DAN PEMBAHASAN}

Sampel pada penerapan Program Edukasi ini adalah sebanyak 30 sampel pasien dengan diabetes mellitus type 2 di RSIJ Cempaka Putih, dan RS Sentra Medika Cikarang yang memenuhi kriteria sebagai berikut:

1. Memiliki setidaknya dua bulan perawatan dan rencana tindak lanjut di klinik dewasa

2. Dapat berbicara, membaca dan memahami bahasa Indonesia 
3. Dapat dihubungi melalui telepon

4. Pasien tanpa komplikasi ulkus namun berisiko terkena ulkus kaki dengan klasifikasi tidak ada riwayat ulserasi kaki sebelumnya, tidak ada kelainan bentuk kaki, sirkulasi ekstremitas bawah normal : pedis dorsal dan denyut tibialis posterior, kondisi normal pada sensasi perlindungan: di lakukan tes dengan monofilament.

Hasil karakteristik responden menurut umur ditundukkan pada tabel 1 sebagai berikut :

Tabel 1. Distribusi Karakteristik Responden.

\begin{tabular}{lcc}
\hline Variabel & Jumlah & Persentase (\%) \\
\hline Pendidikan & & \\
$>65$ tahun & 4 & 13.4 \\
$\leq 65$ tahu & 26 & 86.6 \\
\hline Jenis Kelamin & & \\
Laki-laki & 14 & 46.6 \\
Perempuan & 16 & 53.4 \\
\hline Lama Sakit DM & & \\
$\geq 5$ tahun & 17 & 56.6 \\
$<5$ tahun & 13 & 43.3 \\
\hline
\end{tabular}

Dari table 1 di dapatkan informasi bahwa responden terbanyak berusia di atas sama dengan 65 tahun yaitu sebanyak 26 responden (86.6\%), berjenis kelamin perempuan sebanyak 16 orang (53.4\%), dan mengetahui menderita penyakit diabetes mellitus lebih dari 5 tahun sebanya 17 responden (56.6\%).
Tabel 2. Distribusi Perilaku Perawatan Kaki

Responden di Rumah

\begin{tabular}{lcc}
\hline Variabel & Jumlah & Persentase (\%) \\
\hline Repson Pasien & & \\
Baik : & & \\
Perawatan kaki & 28 & 93.4 \\
di lakukan & & \\
dengan baik & & \\
danrutin di & \\
rumah & & \\
\hline
\end{tabular}

\section{Respon Pasien}

\section{Kurang Baik :}

Perawatan kaki

2

6.6

tidak di lakukan

dengan rutin da

benar di rumah

Dari table 2 di dapatkan informasi bahwa perilaku perawatan kaki responden setelah di berikan intervensi edukasi perawatan kaki, pemberian booklet, dan pemberian alat perawatan kaki hamper seluruh responden yaitu 28 responden (93.4\%) melakukan perawatan kaki di rumah dengan baik dan rutin. 
Tabel 3. Distribusi resiko terjadinya luka (ulserasi) sesudah dan sebelum intervensi

\begin{tabular}{|c|c|c|c|c|}
\hline \multirow[t]{2}{*}{$\begin{array}{c}\text { Jenis } \\
\text { Pengkajian } \\
\text { pada kaki }\end{array}$} & \multicolumn{2}{|c|}{$\begin{array}{c}\text { Pra } \\
\text { Intervensi } \\
\text { ( Minggu I ) }\end{array}$} & \multicolumn{2}{|c|}{$\begin{array}{c}\text { Post } \\
\text { Intervensi } \\
\text { ( Minggu IV) }\end{array}$} \\
\hline & Jumlah & $\%$ & Jumlah & $\%$ \\
\hline \\
\hline \multicolumn{5}{|l|}{ Kaki : } \\
\hline Ada & 20 & 66.7 & 22 & 个6.6 \\
\hline Tidak Ada & 10 & 33.3 & 8 & Ada \\
\hline \multicolumn{5}{|l|}{ Kondisi Kuku : } \\
\hline Baik & 16 & 53.3 & 22 & $\uparrow 20$ \\
\hline Tidak Baik & 14 & 46.7 & 8 & Baik \\
\hline \multicolumn{5}{|l|}{ Kondisi Kulit : } \\
\hline Baik & 12 & 40 & 15 & 个6.6 \\
\hline Kering & 18 & 60 & 13 & Tidak \\
\hline Tidak Utuh & 0 & 0 & 2 & utuh \\
\hline \multicolumn{5}{|l|}{ Rambut Kaki : } \\
\hline Ada & 19 & 63.3 & 22 & $\uparrow 10$ \\
\hline Tidak ada & 11 & 36.7 & 8 & $\begin{array}{l}\text { Tidak } \\
\text { ada }\end{array}$ \\
\hline \multicolumn{5}{|l|}{ Resiko Ulkus : } \\
\hline Rendah & 21 & 70 & 18 & $\uparrow 6.6$ \\
\hline Sedang & 7 & 23.3 & 9 & Sedang \\
\hline \multirow[t]{2}{*}{ Tinggi } & 2 & 6.7 & 3 & $\uparrow 3.3$ \\
\hline & & & & Tinggi \\
\hline Total & 30 & 100 & 30 & 100 \\
\hline
\end{tabular}

Dari table 3 di dapatkan data bahwa ada peningkatan jumlah responden yang mengeluh pada kaki nya pada minggu ke-4 yaitu penambahan 2 responden (6.6\%), peningkatan kondisi kuku membaik sebanyak 6 responden (20\%), peningkatan kondisi kulit tidak utuh menjadi 2 responden (6.6\%), kondisi rambut kaki membaik 3 reponden (10\%), resiko ulkus sedang meningkat 2 responden $(6.6 \%)$ dan resiko ulkus tinggi meningkat 1 responden (3.3\%).

\section{SIMPULAN}

Kesimpulan dalam penerapan Evidance Based Nursing ini adalah :

a. Karakteristik Responden dalam pelaksanaan Evidance Based Nursing (EBN) ini adalah berusia 65 tahun sebanyak 26 responden (86.6\%), berjenis kelamin perempuan sebanyak 16 responden (53.4\%), dan lama menderita diabetes mellitus lebih dari 5 tahun sebanyak 17 responden (56.6\%)

b. Perilaku perawatan kaki responden di rumah sebagian besar baik yaitu melakukan perawatan kaki di rumah dengan baik dan rutin di lakukan di rumah sebanyak 28 responden (93.4\%)

c. Resiko terjadinya ulser pada minggu ke4 di bandingkan pada minggu ke-1 meningkat menjadi kategori sedang sebanyak 2 responden $(6.6 \%)$ dan meningkat menjadi kategori tinggi sebanyak 1 responden (3.4\%).

Perawat di harapkan dapat meningkatkan komunikasi efektif dengan pasien dan keluarga sehingga dapat meningkatan frekuensi dan kualitas promotive kesehatan mengenai penyakit diabetes mellitis terutama pencegahan komplikasi diabetes mellitus. Dan jika komplikasi sudah terjadi, di harapkan pasien dan keluarga di berikan informasi mengenai penanganan dan pencegahan komplikasi lanjutan 


\section{DAFTAR PUSTAKA}

Mcbride, E., Hacking, B., O'Carroll, R., Young, M., Jahr, J., Borthwick, C., Callander, A., \& Berrada Z.(2016). Increasing patient involvement in the diabetic foot pathway: a pilot randomized controlled trial. Diabet Med

Sharoni, S.K.A., Abdul Rahman, H., Minhat, H.S., Shariff-Ghazali, S., \& Ong, M.H.A. (2017). A self-efficacy education programme on foot self-care behaviour among older patients with diabetes in a public long-term care institution, Malaysia: A quasi-experimental pilot study. BMJ Open,

WHO. (2018). World Population Ageing the United Nations, www.un.org/en/ development/desa/ population/.../pdf/ageing/ WPA2015_Re.

Saleh, N.M., Shebl, A., Hatata, E., \& Refiei, M. (2012). Impact of educational program about foot care on knowledge and self-care practice for diabetic older adult patients. Journal of American Science

Mohammedi, K., Woodward, M., Hirakawa, Y., Zoungas, S., Colagiuri, S., Hamet, P., Harrap, S., Poulter, N., Matthews R.D., Marre, M., \& Chalmers, J.( 2016)." Presentations of major peripheral arterial disease and risk of major outcomes in patients with type 2 diabetes: results from the ADVANCE-ON study". Cardiovasc Diabetol

Barrett, E.J., Liu, Z., Khamaisi, M., King, G.L., Klein, R., Klein, B.E., Hughes, T.M., Craft, S., Freedman, B.I., Bowden, D.W., Vinik, A.I., \& Casellini, C.M.(2017). Diabetic Microvascular Disease: An Endocrine Society Scientific Statement. J Clin Endocrinol Metab,

Vileikyte, L., Gonzalez, J. S., Leventhal, H., Peyrot, M. F.,Rubin, R. R., Garrow, A., I \& Boulton, A. J. M. (2006). Patient Interpretation of Neuropathy (PIN) questionnaire: An instrument for assessment of cognitive and emotional factors associated with foot self-care. Diabetes Care

Bandura, A.(1977). Self-efficacy: toward a unifying theory of behavioral change. Psychol Rev.

Bandura, A.(1997). Self-efficacy: the exercise of control. New York: W. H. Freeman and Company.

Morey-Vargas, O.L., \& Smith, S.A.(2015). BE SMART: strategies for foot care and prevention of foot complications in patients with diabetes. Prosthet Orthot Int,

Bai, Y.L. , \& Chiou, Y.Y. (2009). Chang self- 
care behavior and related factors in older people with Type 2 diabetes. J Clin Nurs.

Elbert, S., Huang, M.D., Laiteerapong, N., Jennifer, Y., Liu, John, M., Howard, H., Moffet, \& Karter, J. (2014). Rates of Complications and Mortality in Older Patients With Diabetes mellitus the Diabetes and Aging Study. JAMA Intern Med,

Gaumer, A.S., \& Noonan, P.M. (2018). Selfefficacy formative questionnaire. In The skills that matter: Teaching interpersonal and intrapersonal competencies in any classroom. Thousand Oaks, CA: Corwin.

Lincoln, N., Radford, K., Game, F., \& Jeffcoate, W. (2008). Education for secondary prevention of foot ulcers in people with diabetes: a randomized controlled trial. Diabetologia.

McInnes, A., Jeffcoate, W., Vileikyte, L., \& Game, F.(2011). Foot care education in patients with diabetes at low risk of complications: $\quad$ a consensus statement. Diabet Med.

Wendling, S., \& Beadle, V. (2015). The relationship between self-efficacy and diabetic foot self-care. J Clin Transl Endocrinol

Waxman, R., Woodburn, H., Powell, M., Woodburn, J., Blackburn, S., \& Helliwell, P.(2003). FOOTSTEP: $a$ randomized controlled trial investigating the clinical and cost effectiveness of a patient selfmanagement program for basic foot care in the elderly. Journal of Clinical Epidemiology.

Guvenc, G., Akyuz, A., \& Acikel C.(2010). Research Methodology: Health Belief Model Scale for Cervical Cancer and Pap Smear Test: Psychometric Testing. Journal of Advanced Nursing

Lenz, E.R., \& Shortridge-Baggett, L.M. (2012). Self-efficacy in nursing: research and measurement perspectives. New York: Springer Publishing Company.

Edmonds, M.E., \& Foster, A.V.M.(2014). Managing Stage 1: The Normal Foot. Managing the Diabetic Foot

Eigenmann, C.A., Skinner, H., \& Colagiuri, R.(2013). Development and validation of a diabetes knowledge questionnaire. Practical Diabetes International.

O'Brien, M.J., Perez, A., Alos, V.A., et al.(2015). The feasibility, acceptability, and preliminary effectiveness of a Promotora-Led Diabetes Prevention Program (PL-DPP) in Latinas: a pilot study. Diabetes Educ

Kattan, W., \& Thomas, T. H.(2018). Factors Influencing Variations in Hospitalization for Diabetes with 
Hypoglycemia, Journal of Clinical Gebremedhin, T., Workicho, A., \& Angaw, Medicine D.A. (2019). Health-related quality of

Dorresteijn, J.A.N., Kriegsman, D.M.W., life and its associated factors among Assendelft, W.J.J., \& Valk, G.D. (2014). adult patients with type II diabetes Patient education for preventing attending Mizan Tepi University diabetic foot ulceration. Cochrane Teaching Hospital, Southwest Database of Systematic Reviews.

Ethiopia. BMJ Open Diabetes

Toh, H.J., et al. (2017). Factors associated Research and Care with prolonged length of stay in older patients. Singapore Medical Journal Kalyani, R.R., Golden S.H., \& Cefalu, W.T. (2017). Diabetes and Aging: Unique Considerations and Goals of Care. Diabetes Care, 